\title{
BENTUK PERTUNJUKAN SENI GEMBLAK DOR DI LAMONGAN
}

\author{
Welly Suryandoko \\ Universitas Negeri Surabaya \\ wellysuryandoko@unesa.ac.id
}

\begin{abstract}
ABSTRAK
Masyarakat Lamongan umumnya hanya mengenal seni pertunjukan Sandur dan Tayub. Selain kedua seni pertunjukan tersebut, juga terdapat seni pertunjukan Gemblak Dor yang tidak kalah menariknya. Sebagian orang mengartikan bahwa Gemblak berasal dari Ponorogo yaitu istilah yang mengacu pada peliharaan seorang warok yang dulu sebagai pelaku penunggang kuda jathilan yang ada dalam kesenian reog Ponorogo. Sedangkan Gemblak Dor di desa Slaharwotan merupakan seni pertunjukan rakyat karena tumbuh dan berkembang di lingkungan masyarakat. Istilah Gemblak Dor berasal dari kata "Mblak" yang berbunyi dari instrumen kendangnya dan "Dor" berasal dari isntrumen jidor, sehingga masyarakat desa Slaharwotan menyebutnya Gemblak Dor. Permasalah penelitian ini adalah, (1) bagaimana asalusul pertunjukan Gemblak Dor di desa Slaharwotan? (2) bagaimana struktur pertunjukkan Gembak Dor? (3) Bagaimana fungsi seni pertunjukan Gemblak Dor di masyarakat sekitar? Tujuan penelitian, untuk mendeskripsikan asal mula munculnya seni pertunjukan Gemblak Dor di Desa Slaharwotan, bentuk pertunjukan, serta fungsi seni pertunjukan Gemblak Dor di dalam masyarakat sekitar.Metode penelitian ini menggunakan deskriptif kualitatif. Lokasi penelitian di desa Slaharwotan, kecamatan Ngimbang, Kabupaten Lamongan. Teknik pengumpulan data yang digunakan adalah wawancara, observasi, dan dokumentasi. Analisis data yang digunakan adalah domain dan taksonomi. Validitas data yang digunakan adalah triangulasi sumber dan metode. Hasil dari penelitian ini :seni pertunjukan Gemblak Dor merupakan akulturasi budaya yang dibawa masuk ke Lamongan oleh sekelompok pengamen dari Nganjuk dan Jombang, berkembang di desa Slaharwotan kecamatan Ngimbang kabupaten Lamongan. Seni pertunjukan Gemblak Dor terdiri dari penari ayon-ayon, jaranan, jepaplokpentul dan tembem, dan genderuwo. Struktur pertunjukannya terdiri pembukaan, atraksi pertunjukan, dan penutup. Seni pertunjukan Gemblak Dor memiliki fungsi primer yang terdiri dari sarana ritual, hiburan, dan presentasi estetis. Sedangkan fungsi sekunder terdiri dari pengikat solidaritas kelompok masyarakat dan sarana komunikasi.Selain fungsi primer dan sekunder terdapat fungsi yaitu sebagai respon fisik yang dapat memberikan stimulus anggota jasmani.
\end{abstract}

Kata kunci: Seni pertunjukan Gemblak Dor, struktur pertunjukan

\section{ABSTRACT}

The Lamongan community generally only knows the performing arts of Sandur and Tayub. In addition to the two performing arts, there is also a performance art Gemblak Dor that is no less interesting. Some people interpret that Gemblak 
comes from Ponorogo, a term that refers to the warok's pet who used to be a jathilan rider in the Ponorogo reog art. While Gemblak Dor in Slaharwotan village is a folk art performance because it grows and develops in the community. The term Gemblak Dor comes from the word "Mblak" which sounds from the instrument and "Dor" comes from the instrument jidor, so that the people of Slaharwotan village call it Gemblak Dor. The problem of this research is, (1) what is the origin of the Gemblak Dor performance in Slaharwotan village? (2) how is the structure of the Gembak Dor show? (3) What is the function of Gemblak Dor's performing arts in the surrounding community? The purpose of the study, to describe the origin of the emergence of Gemblak Dor performance in Slaharwotan Village, the form of performances, as well as the function of performing arts Gemblak Dor in the surrounding community. The method of this research used descriptive qualitative. Research location in Slaharwotan village, Ngimbang sub-district, Lamongan Regency. Data collection techniques used were interviews, observation, and documentation. Analysis of the data used is the domain and taxonomy. The data validity used is source triangulation and method. The results of this study: Gemblak Dor performance art is an acculturation of culture brought into Lamongan by a group of singers from Nganjuk and Jombang, developing in the village of Slaharwotan, Ngimbang district, Lamongan district. Gemblak Dor's performing arts consist of ayon-ayon dancers, jaranan, jepaplokpentul and tembem, and genderuwo. The structure of the performance consists of opening, show attraction, and closing. Performing arts Gemblak Dor has a primary function consisting of means of ritual, entertainment and aesthetic presentation. While the secondary function consists of binding community group solidarity and means of communication. In addition to primary and secondary functions there is a function that is as a physical response that can provide stimulus to physical members.

Keywords: Performing arts Gemblak Dor, performance structure

\section{PENDAHULUAN}

Gemblak Dor merupakan salah satu seni pertunjukan tradisional Lamongan. Segala bentuk dan fungsinya berkaitan erat dengan masyarakatnya, dimana seni pertunjukan itu tumbuh hidup dan berkembang di masyarakat. Seni pertunjukan itu, juga merupakan produk sosial yang mempunyai fungsi sebagai sarana komunikasi yang bermanfaat bagi masyarakat. Seni pertunjukan Gemblak Dor ini menggunakan kuda yang terbuat dari anyaman bambu.

Di kabupaten Ponorogo juga terdapat Gemblak yang merupakan peliharaan dari seorang warok yang memiliki ciri khas tersendiri, yaitu orang Gemblak selalu terlihat bersih, memiliki kepribadian yang baik karena semua perilaku gemblak diatur, dari tutur kata harus memakai bahasa krama,selain itu seorang gemblak mempunyai gigih tlasah, yaitu gigi taring di sebelah kiri yang dilapisi dengan platina sebagai aksesoris agar mempesona, serta seorang Gemblak mempunyai pasang 
pengasihan atau susuk, bisa pada bibir, pipi, ataupun mata. Di kabupaten Lamongan arti Gemblak Dor adalah seni perunjukan berarti seni pertunjukan yang terdiri dari, jaranan, penari ayon-ayon, penthul dan themben, jepaplok, dan genderuwonan. Gemblak Dor berasal dari kata "Mblak" yang berbunyi dari instrumen kendangnya dan "Dor" berasal dari instrumen jidor.

Ciri khas dari Gemblak Dor di kabupaten Lamongan ini sebelum pertunjukan dimulai kuda diparkir ditengah-tengah penonton kemudian sebelum melakukan atraksi didahului oleh 2 penari ayon-ayon, kuda atau jaran yang digunakan sebagai propeti oleh penari cara memakainya dikenakan di pinggang, ini yang membuat berbeda dengan Kepang Dor pada pertunjukannya para penari kuda langsung melakukan atraksi layaknya penari yang sedang kesurupan, sedangkan dalam Jaran Dor, kuda yang dikenakan oleh penari diberi tali kemudian digantungkan di bahu penari. Peneliti tertarik pada perbedaan tersebut sehingga ingin meneliti lebih lanjut terutama dalam bentuk pertunjukan Gemblak Dor dan fungsinya di masyarakat desa Slaharwotan.

Seni pertunjukan Gemblak Dor yang hidup di wilayah Lamongan selatan meliputi, wilayah kecamatan Modo, Bluluk, Sukorame, dan Ngimbang. Pada era globalisasi saat ini banyak bentuk-bentuk seni pertunjukan tradisional termasuk jenis Gemblak Dor yang mulai banyak ditinggalkan pendukungnya dan kurang diminati masyarakat, untuk menghadapi permasalahan tersebut Gemblak Dor yang ada di kecamatan Modo sekarang dikemas menjadi satu dengan seni pertunjukan Sandur seperti dramatari yang memiliki alur cerita dengan beberapa penokohan. Seni pertunjukan Gemblak Dor di kecamatan Bluluk dan Sukorame sudah tidak eksis lagi, penyebab terjadinya hal tersebut diantaranya karena proses regenerasi yang tidak kontinyu. Pemain Gemblak Dor banyak yang pergi merantau ke kota-kota serta kurangnya mampu menyesuaikan perkembangan selera masyarakat penikmatnya sehingga, mengalami perpecahan kelompok, sebagian kelompok seni pertunjukan di kecamatan Bluluk dan Sukorame yang para pemainnya tidak merantau begabung menjadi satu dengan kelompok Seni Pertunjukan Gemblak Dor yang ada di Desa Slaharwotan Kecamatan Ngimbang. (wawancara dengan bapak Tatik, pimpinan seni Pertunjukan Gemblak Dor, tanggal 16 Maret 2014 ) 
Peneliti tertarik pada kelompok seni pertunjukan Gemblak Dor pimpinan bapak Tatik yang ada di desa Slaharwotan kecamatan Ngimbang. Ketertarikan tersebut karena Gemblak Dor di desa Slaharwotan keberadaannya masih sangat diminati oleh masyarakat, hal ini terbukti dengan banyaknya permintaan pertunjukan Gemblak Dor (tanggapan). Masyarakat desa tersebut masih percaya dengan adanya roh-roh halus dan pendukung seni pertunjukan Gemblak Dor di desa Slaharwotan kecamatan Ngimbang ini sangat beragam, mulai anak-anak, para remaja baik laki-laki maupun perempuan, hingga yang tua semuanya berbaur dan bekerjasama tampak kompak sebagai satu kesatuan organisani seni pertunjukan yang masing - masing terlihat kompak dalam menjalankan peranannya secara profesional.

Desa Slaharwotan merupakan desa yang tedapat di Kecamatan Ngimbang, Kabupaten Lamongan. Kehidupan masyarakat desa Slaharwotan mayoritas berlatar belakang agraris dengan mata pencaharian sebagai petani. Selain bercocok tanam masyarakat desa Slaharwotan juga beternak sapi, kambing, dan ayam, sehingga pola hidupnya masih sangat sederhana. Masyarakat Desa Slaharwotan memeluk agama Islam yang kuat dan lekat, meskipun masyarakatnya memeluk agama islam tetapi karna budaya masyarakat diterapkan oleh masyarakat sehingga meskipun masih beragama islam namun masih percaya dengan adanya animisme dan dinamisme. Kehidupan masyarakat desa Slaharwotan masih tradisional dan selalu mengutamakan kerukunan dengan penuh rasa kekeluargaan, gotong royong, dan toleransi dalam melakukan interaksi dengan sesama. Keyakinan terhadap adat istiadat, maupun seni pertunjukan juga masih lestari, yang dapat dilihat dari caranya mempertahankan seni pertunjukan yang dimiliki sebagai warisan budaya. Salah satu seni pertunjukan di desa Slaharwotan yang masih eksis adalah seni pertunjukan Gemblak Dor.

Penyelenggaraan seni pertunjukan Gemblak Dor di Desa Slaharwotan, Kecamatan Ngimbang ini biasanya di gunakan oleh warga masyarakat sebagai wujud rasa syukur karna hasil panen yang melimpah. Berangkat dari fenomena diatas, peneliti tertarik untuk mendeskripsikan asal usul sampai terbentuknya seni pertunjukan Gemblak Dor di Desa Slaharwotan, Kecamatan Ngimbang, bentuk pertunjukannya dan fungsi Gemblak Dor bagi masyarakat Desa Slaharwotan, Kecamatan Ngimbang. 
Dari rumusan masalah diatas, permasalahan yang ada adalah: (1) Bagaimana asal-usul seni pertunjukan Gemblak Dor di desa Slaharwotan kecamatan Ngimbang kabupaten Lamongan? (2) Bagaimana struktur pertunjukan seni pertunjukan Gemblak Dor di Desa Slaharwotan, Kecamatan Ngimbang, Kabupaten Lamongan? (3) Bagaimana fungsi seni pertunjukan Gemblak Dor di masyarakat?

Tujuan dari penelitian ini yaitu untuk mendeskripsikan asal asul dan bentuk pertunjukan Gemblak Dor di desa Slaharwotan dan mendeskripsikan fungsi Gemblak Dor untuk masyarakat sekitar. Penelitian ini juga bermanfaat bagi seniman, peneliti, masyarakat sekitar, dan pemerintah daerah setempat.

Keterbatasan penelitian diperlukan agar peneliti tidak meluas, tetapi ruang lingkup difokuskan pada penjabaran sekitar permasalahan. Pada penelitian ini, peneliti memberikan batasan ruang lingkup pada Seni Pertunjukan Gemblak Dor di desa Slaharwotan kecamatan Ngimbang kabupaten Lamongan dengan fokus permasalahan yaitu : asal mula munculnya seni pertunjukan Gemblak Dor di desa Slaharwotan kecamatan Ngimbang kabupaten Lamongan, bentuk pertunjukan yang meliputi sistematika pertunjukan Gemblak Dor pada umumnya, elemen gerak, tata rias, tata busana, musik pengiring dan pendukung lainnya dalam pertunjukan tersebut serta fungsi seni pertunjukan tersebut bagi masyarakat sekitarnya.

\section{Asal-Usul}

Istilah asal-usul dalam buku Pertumbuhan Seni Pertunjukan Sedyawati Edi (1981:150) menyatakan untuk mengungkap asal usul adalah pemakain kritis data kuno terutama filologis, berita-berita, naskah-naskah Jawa maupun prasasti-prasasti, dan mencoba merekontruksi kembali penyajian seni atas dasar deskripsi dan etimologi. Indonesia adalah istilah, asal keturunan, sebab yang mula-mula sekali. Asal-usul yang dimaksud dalam peneliti adalah munculnya seni pertunjukan Gemblak Dor di Desa Slaharwotan Kecamatan Ngimbang Kabupaten Lamongan.

\section{Bentuk Pertunjukan}

Dalam buku Estetika sebuah Pengantar Djelantik (1999:77) menyatakan bahwa bentuk merupakan wujud yang mengacu pada kenyataan yang nampak secara kongkrit (dapat dipersepsi dengan mata atau telingan) maupun kenyataan yang tidak nampak secara kongkrit, yang abstrak, yang hanya bisa dibayangkan. Menurut Robby Hidayat dalam bukunya berjudul Wawasan Seni Tari (2005:26). Bentuk pertunjukan 
adalah suatu bentuk proses penggarapan yang mengantarkan pada suatu koreografi tertentu sehingga pada akhir proses garapan, seorang koreografer dapat memahami dengan benar bentuk koreografi yang telah diproduksi. Bentuk adalah aspek yang secara estetis dinilai oleh penonton, disini penonton tidak melihat setiap elemen tetapi melalui kesan yang menyeluruh. Bentuk pertunjukan, dalam penelitian ini yang dimaksud pemaparan mengenai keseluruhan rangkain pementasan seni pertunjukan Gemblak Dor secara lengkap dan utuh yang meliputi seluruh elemen bentuk seni pertunjukan yang tampak di atas pentas yang ditampilkanserta tampak dari proses pertunjukan yang dilakukan.

Dalam penelitian ini bentuk pertunjukan yang dimaksud yakni keseluruhan pertunjukan Gemblak Dor sebagai hubungan yang paling berkaitan antara elemenelemen pertunjukannya yang terdiri dari:

\section{a. Gerak}

Gerak merupakan bahan baku yang paling penting dan utama dalam tari, tetapi tidak semua gerak dapat dikatakan sebagai gerak tari. Menurut Sudarsono (1998:42) menyebutkan bahwa berdasarkan maksudnya gerak dapat dibagi menjadi dua yaitu gerak maknawi dan gerak murni. Gerak maknawi dapat diartikan sebagai gerak tari yang sudah distiril dan mengandung arti, sedangkan gerak murni lebih merujuk pada gerak yang digunakan pada keseharian. Sedangkan menurut M. Djelantik dalam bukunya yang berjudul Estetika Sebuah Pengantar, gerak merupakan unsur penunjang yang paling besar peranannya dalam seni tari. Wahyudiyanto (2008:14), berpendapat bahwa dalam bergerak terdapat unsur-unsur gerak yang terdiri dari:

1) Bahan yang bergerak

2) Energy atau tenaga yang menggerakkan bahan

3) Area atau ruang tempat berpindahnya bahan

4) Waktu yang diperhatikan sebagai ukuran untuk menetukan seberapa lama tejadinya proses berpindahnya bahan.

\section{b. Tata Pentas}

Menurut Padmodarmaya (1988:26-27), kata "pentas" di sini adalah sebuah tempat yang dipergunakan untuk mempertunjukan suatu pameran yang dengan sadar mengisyaratkan subuah nilai kesenian. Pentas disini belum tentu merupakan 
panggung, apabila yang dimaksud panggung merupakan suatu tempat dengan ketinggian tertentu. Pentas dapat berupa sebuah tempat yang mendatar rata saja, misalnya sebuah halaman rumah yang dipergunakan sebagai tempat pertunjukan

\section{c. Tata Rias dan Busana}

Tata rias dan busana adalah aspek visual pendukung tari yang secara langsung dapat dinikmati oleh penonton. Fungsi tata rias dan busana sangat erat dengan tema atau karakter tokoh sehingga dapat memperjelas karakter tokoh tersebut. Tema sebuah pertunjukan biasanya sering disimbolkan dengan tata rias dan busana.

\section{1) Tata Rias}

Menurut Hidayat (2005:60), tata rias adalah satu unsur koreografi yang berkaitan dengan karakteristik tokoh. Tata rias berperan penting dalam membentuk efek wajah penari yang diinginkan (sesuai konsep koreografi) ketika lampu panggung menyinari penari. Penggunaan tata rias pada sebuah koreografi memiliki alasan-alasan tertentu. Tata rias untuk koreografi adalah salah satu unsur kelengkapan yang penting karena disebabkan oleh dua faktor yang mendasar, yaitu :

a) Tata rias merupakan bagian yang berkaitan dengan pengungkapan tema atau isi cerita, maka tata rias merupakan salah satu aspek visual yang mampu menuntun interpertasi penonton pada obyek estetik yang disajikan atau sesuatu yang ditarikan.

b) Tata rias sebagai salah satu upaya untuk memberikan ketegasan atau kejelasan dari anatomi wajah, karena sajian tari pada umumnya disaksikan oleh penonton dengan jarak yang cukup jauh yaitu 5-7 meter.

Menutut Jazuli (1994:19), tata rias panggung dibedakan menjadi dua, yaitu :

1) Tata rias panggung atau pentas biasa (tertutup)

Pada peggunaan tata rias panggung dianjurkan lebih tegas dan jelas garis-garisnya serta lebih tebal, karena biasanya penonton melihat pertunjukan dalam jarak yang cukup jauh.

2) Tata rias panggung arena atau terbuka

Tata rias panggung arena ini tidak terlalu menggunakan rias yang tebal dan yang lebih utama halus, nampak rapi dan halus, karena seringkali penonton berada lebih dekat dengan pertunjukan. 


\section{2) Tata Busana}

Tata busana merupakan pakaian atau kostum yang dikenakan oleh penari yang disesuaikan oleh tokoh serta karakter yang diperankan.Busana pentas meliputi semua busana dan perlengkapannya baik yang kelihatan langsung maupun tidak langsung oleh penonton.

Fungsi busana adalah untuk mendukung tema atau isi tari, dan untuk memperjelas peranan-peranan dalam suatu sajian tari.Busan yang baik bukan hanya untuk sekedar penutuh tubuh semata, tetapi juga harus bisa mendukung desain ruang pada saat penari sedang menari. Jazuli (1994:17) berpendapat bahwa dalam penataan dan penggunaan busana tari senantiasa mempertimbangan hal-hal sebagai berikut :

1) Busana tari hendaknya enak dipakai

2) Penggunaan busana selalu mempertimbangkan isis atau tema tari sehingga bisa menghadirkan suatu kesatuan/ keutuhan antara tari dan tata busananya.

3) Peñata busana hendaknya dapat merangsang imajinasi penonton.

4) Desain busana harus memperhatikan bentuk-bentuk gerak.

5) Busana hendaknya dapat memberi proyeksi kepada penarinya.

6) Keharmonisan dalam pemilihan atau memperpadukan warna sangat penting, terutama harus diperhatikan efeknya terhadap tata cahaya.

\section{d. Properti}

Menurut Hidayat (2005:58-59), property adalah istilah alat-alat pertunjukan. Pengertian tersebut mempunyai dua tafsiran yaitu properti sets dan properti sebagai alat bantu berekspresi. Properti merupakan suatu bentuk peralatan penunjang gerak wujud ekspresi.

\section{e. Tokoh}

Dalam seni pertunjukan Gemblak Dor yang berada di Desa Slaharwotan, Kecamatan Ngimbang, Kabupaten Lamongan, terdiri dari jeplapok, genderuwo, kuda lumping, topeng penthul dan tembem.

\section{f. Musik Pengiring}

Musik dalam tari meupakan pasangan yang bisa terpisahkan karena berasal dari sumber yang sama, yaitu dorongan atau naluri ritmis. Kehadiran aspek musical tidak bisa diabaikan, karena antara gerak dan music dirasakan sangat lekat untuk membentuk rasa tari. 
Menurut Hidayat (2005:53), fungsi musik dapat dikelompokkan menjadi tiga, yaitu :

1) Musik sebagai iringan atau partner

2) Musik sebagai penegas gerak

3) Musik sebagai ilustrasi

Teori yang dipaparkan di atas digunakan untuk mendeskripsikan bentuk pertunjukan Gemblak Dor di desa Slaharwotan, kecamatan Ngimbang kabupaten Lamongan.

\section{g. Penonton}

Menurut Brandon James R (2003:335) penonton adalah ibarat samudra dan rombongan-rombongan seni pertunjukan adalah ikan yang berenang di dalamnya.

\section{h. Sistematika Pertunjukan}

Seni Pertunjukan Gemblak Dor ini memiliki sistematika pertunjukan yang harus dilakukan yaitu:

1. Pembukaan

Sebelum pertunjukan berlangsung, para pawang mengadakan slametan di sekitar area yang akan digunakan untuk pertunjukan. Dimana mereka meminta doa agar pertunjukan tersebut berjalan dengan lancar tanpa halangan apapun. Makna dari slematan adalah memberikan suatu penghormatan kepada orang lain atau kepada zat lain yang ada pada lingkungan diri manusia. Maka dari itu setiap penyelenggaraan seni pertunjukan Gemblak Dor selalu disertai slametan yang diarahkan kepada yang menciptakan kehidupan yaitu Tuhan Yang Maha Esa untuk memohon doa restu atau perlindungan. Selain seorang pawang, orang yang menanggap pertunjukan tersebut ketika mengadakan slametan juga mengundang para tetangga sekitar khususnya para laki-laki. Pada umumnya sesaji slametan dalam pementasan Gemblak Dor menggunakan nasi kuning (tumpeng) dan ayam panggang. Namun, pementasan Gemblak Dor yang diadakan di desa Slaharwotan, pada tanggal 27 Mei 2014, yaitu untuk pelepas nadzar atas kelahiran anak pertama salah satu masyarakat desa Slaharwotan, menggunakan sesaji brokohan. , Setelah mengadakan slametan pertunjukan Gemblak Dor dimulai dengan mempersiapkan kuda yang menjadi properti diparkir ditengah-tengah area pertunjukan. Sebelum pertunjukan dimulai pawang Gemblak Dor melakukan ritual membakar menyan dan memutar-mutarkan pecut diatas menyan guna menyetir para Pemain Gemblak Dor yang sedang kesurupan. 
2. Pertunjukan

Pertunjukan pertama diawali pementasan Ayon-ayon, kemudian jaranan, adegan jepaplok, pentul tembem, dan genderuwo.

3. Penutupan

Penutupan seni pertunjukan Gemblak Dor ini diakhiri dengan keluarnya semua tokoh-tokoh yang ikut serta dalam pertunjukan tersebut, berbaris berjajar kemudian pemimpin pertunjukan mengucapkan salam penutup, dan penonton bubar dari area pertunjukan. Setelah melakukan penghormatan para pemain melakukan do'a bersama sebagai ungkapan terimakasih kepada Tuhan Yang Maha Esa karena telah diberi kelancaran dalam pementasan tersebut.

\section{Teori Fungsi Seni Pertunjukan}

Fungsi seni pertunjukan menurut Soedarsono (2001:170-172) dapat dikelompokkan menjadi dua yaitu fungsi primer dan sekunder. Fungsi primer dikelompokkan menjadi tiga :

a. Sebagai sarana ritual, penikmatnya adalah kekuatan-kekuatan yang tak kasat mata.

b. Sebagai sarana hiburan pribadi, penikmatnya adalah pribadi-pribadi yang melibatkan diri dalam pertunjukan.

c. Sebagai presentasi estetis, yang pertunjukannya harus dipresentasikan atau disajikan kepada penonton.

Fungsi sekunder, apabila pertunjukan itu bertujuan bukan sekedar untuk dinikmati tetapi untuk kepentingan lain seperti:

a. Sebagai pengikat solidaritas kelompok masyarakat.

b. Sebagai pengikat solidaritas bangsa.

c. Sebagai media komunikasi masa.

d. Sebagai media propaganda (keagamaan, politik, program pemerintah, dan lainnya).

Sehubungan pembahasan masalah fungsi seni pertunjukan Gemblak Dor Desa Slaharwotan Kecamatan Ngimbang, tidak dapat dilepaskan dari peran fungsi seni pertunjukan Gemblak Dor tersebut bagi masyarakat. Oleh karena itu, teori fungsi yang digunakan dalam permasalahn fungsi seni pertunjukan tersebut dalam penelitian ini adalah teori - teori, yaitu fungsi seni ditinjau dari primer dan sekunder. 


\section{PEMBAHASAN}

Asal-usul merupakan peristiwa yang ada kaitannya dengan masa lalu yang terjadi dari awal munculnya suatu peristiwa. Menurut Sedyawati (1981-150) asal-usul adalah pemakain kritis data kuno terutama filologis, berita-berita, naskah-naskah Jawa maupun prasasti-prasasti, dan mencoba merekontruksi kembali penyajian seni atas dasar deskripsi dan etimologi. Untuk membahas asal-usul seni pertunjukan Gemblak Dor di desa Slaharwotan kecamatan Ngimbang kabupaten Lamongan maka, harus mengetahui gambaran umum lokasi penelitian dan kehidupan masyarakat sosialnya yaitu masyarakat desa Slaharwotan kecamatan Ngimbang, agar dapat dipahami secara seksama.

\section{Letak Geografis}

Desa Slaharwotan merupakan suatu daerah yang berada di selatan Kabupaten Lamongan. Letak Desa Slaharwotan berjarak kurang lebih tiga kilometer dari pusat kecamatan Ngimbang, lima puluh kilometer dari pusat kabupaten Lamongan. Jarak tempuh dari Desa Slaharworan ke Kota Lamongan, dapat ditempuh dengan menggunakan jasa angkutan umum atau pribadi. Batas wilayah desa Slaharwotan sebelah utara adalah desa Tlemang, sebelah selatan adalah desa Kakat Penjalin, sebelah Barat adalah desa Ngasem dan sebelah Timur adalah desa Druju kecamatan Ngimbang.

\section{Penduduk dan Mata Pencaharian}

Penduduk desa Salaharwotan berjumlah 2.305 jiwa, dengan rincian 1085 laki-laki dan 1220 perempuan. Sebagian besar masyarakat desa Slaharwotan bermata pencaharian sebagai petani. Selain bercocok tanam masyarakat Desa Slaharwotan juga beternak sapi, kambing, dan ayam. Penduduk Desa Salaharwotan berjumlah 2.305 jiwa, dengan rincian 1085 laki-laki dan 1220 perempuan. Sebagian besar masyarakat desa Slaharwotan bermata pencaharian sebagai petani. Selain bercocok tanam masyarakat desa Slaharwotan juga beternak sapi, kambing, dan ayam.

\section{Pendidikan}

Proses pendidikan merupakan program pemerintah dalam rangka meningkatkan kualitas sumber daya manusia. Pembangunan pendidikan bagi masyarakat desa Slaharwotan telah mendapatkan prioritas utama sehingga hasil dan manfaatnya diharapkan dapat menunjang suksesnya pelaksanaan otonomi daerah, yaitu 
pembangunan daerah disegala bidang. Meskipun desa Slaharwotan termasuk desa pelosok paling selatan dari kabupaten Lamongan, namun aspirasi mayarakat Slaharwotan terhadap dunia pendidikan yang lebih tinggi.

Mayoritas pendidikan masyarakat desa Slaharwotan tergolong berpendidikan tinggi, hal ini menandakan bahwa masyarakat desa Slaharwotan mempunyai sumber daya yang maju karena berpendidikan dan dapat diajak berfikir maju untuk mengembangkan desa.

\section{Agama dan Kepercayaan}

Masyarakat desa Slaharwotan menganut agama islam namun masih percaya dengan terhadap mitos-mitos yang berkaitan alam semesta. Sehingga dalam kehidupannya masyarakat desa Slaharwotan masih memberi sesajen di tempat yang disakralkan. Oleh sebab itu masyarakat desa Slaharwotan tergolong masyarakat abangan.

\section{Kesenian}

Bagi masyarakat desa Slaharwotan, seni pertunjukan merupakan sarana hiburan yang kehadirannya sangat dinantikan serta dapat mengundang perhatian masyarakat. Adapun seni pertunjukan yang masih berkembang di masyarakat desa Slaharwotan diantaranya, Tayub, Wayang, dan Gemblak Dor.

Seni pertunjukan tersebut umumnya diselenggarakan pada saat tertentu atau ketika seseorang mempunyai hajatan seperti dalam upacara pernikahan, sunatan, perayaan HUT kemerdekaan RI, penyambutan tamu, dan acara-acara lain. Seni pertunjukan yang ada di desa Slaharwotan masih tetap eksis dan dilestarikan serta mendapat tanggapan yang baik bagi masyarakat sebagaiamana fungsinya. Fungsi tersebut berupa fungsi sosial baik yang bersifat ritual, hiburan maupun presentasi estetis.

\section{Bentuk Pertunjukan}

\section{Pembukaan}

Sebelum pertunjukan berlangsung, para pawang mengadakan slametan di sekitar area yang akan digunakan untuk pertunjukan. Dimana mereka meminta doa agar pertunjukan tersebut berjalan dengan lancar tanpa halangan apapun. Makna dari slematan adalah memberikan suatu penghormatan kepada orang lain atau kepada zat lain yang ada pada lingkungan diri manusia. Maka dari itu setiap penyelenggaraan 
seni pertunjukan Gemblak Dor selalu disertai slametan yang diarahkan kepada yang menciptakan kehidupan yaitu Tuhan Yang Maha Esa untuk memohon doa restu atau perlindungan. Selain seorang pawang, orang yang menanggap pertunjukan tersebut ketika mengadakan slametan juga mengundang para tetangga sekitar khususnya para laki-laki.

Pada umumnya sesaji slametan dalam pementasan Gemblak Dor menggunakan nasi kuning (tumpeng) dan ayam panggang. Namun, pementasan Gemblak Dor yang diadakan di desa Slaharwotan, pada tanggal 27 Mei 2014, yaitu untuk pelepas nadzar atas kelahiran anak pertama salah satu masyarakat desa Slaharwotan, menggunakan sesaji brokohan.

Slametan yang menggunaka sesaji seperti brokohan berisi nasi putih, tumpeng uceng, dan krawu, seperti yang terlihat pada gambar 4.4 dan merupakan sarana penting yang tidak bisa ditinggalkan dalam pertunjukan Gemblak Dor. Slametan ini dimaksudkan agar selama pertunjukan semua pendukung tidak mendapat musibah atau gangguan dari hal yang tidak diinginkan seperti gangguan roh halus.

\section{Pertunjukan}

a) Adegan pertama dalam penampilan Gemblak Dor diawali dengan dua penari Ayon-ayon yang menjadi pembuka pertunjukan. Dua penari ayon-ayon ini menarikan gendhing-gendhing jogetan yang dimainkan oleh pengrawit. Ayonayon berasal dari kata ayu-ayu sehingga, yang menarikan juga berias gagah namun cantik.

b) Adegan Jaranan merupakan pertunjukan inti dalam Gemblak Dor. Penari kuda yang keluar berjumlah dua penari jaranan. Komposisi pola lantai pada keseluruhan pertunjukan yaitu, berjejer berpasangan, berhadapan, dan berderet. Setelah melakukan gerakan-gerakan selama \pm 30 menit pada adegan pertama diakhiri dengan beberapa penari yang melakukan trance atau kesurupan.

Penari Jaranan dalam melakukan trance biasanya memakan ayam hidup yang sudah disediakan di samping tempat pengrawit namun, dalam adegan trance pada pementasan Gemblak Dor berbeda dengan jaranan lainnya, para pemain tidak menyediakan ayam hidup untuk dijadikan makanan. Adegan trance ini merupakan adegan spontanitas tidak direncanakan, sehingga ketika para penari jaranan mengalami trance, mereka memakan apapun yang ada disekitar tempat 
pementasan, misalnya seperti: rumput, pecahan kaca, dan tanaman-tanaman yang ada dalam area pertunjukan.

c) Adegan Jepaplok dan Pentul Tembem

Adegan Jepaplokan, pentul, dan tembem merupakan babak kedua pada pertunjukan Gemblak Dor. Jepaplokan disini dilakukan oleh satu penari. Pada adegan ini Jepaplok, topeng pentul dan tembem keluar secara bersamaan. Pada pementasan Gemblak Dor tokoh jepaplok mempunyai struktur yang berbeda dari jepaplok yang ada pada pementasan jaranan pada umumnya. Jepaplok disini, tidak melakukan gerakkan kiprahan namun hanya meliuk-liukan topeng yang dikenakan dengan membuka dan menutup mulutnya.Tokoh jepaplok juga melakukan adegan trance, sedangkan tokoh topeng penthul dan thembem hanya menari dengan karakter yang gejul,yang sesekali menggoda jepaplok yang mengalami trance.

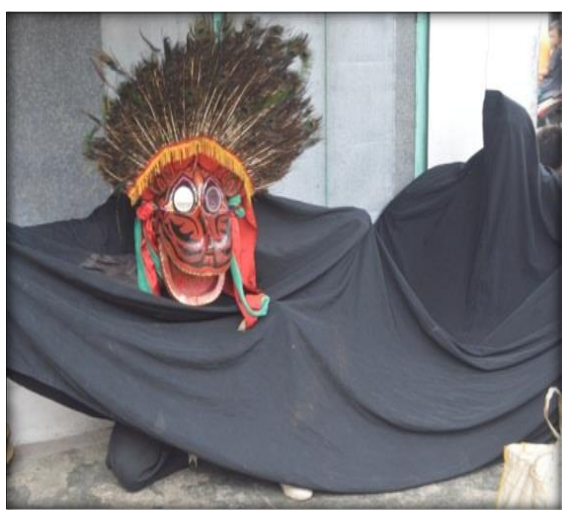

Gambar 1

Jepaplok yang mengalami trance sampai keteras rumah warga

(Dokumentasi Penulis 2017)

Jepaplok merupakan tokoh jahat yang menganggu masyarakat, dapat dilihat dari bentuk topeng dan kostum pada gambar 1. Selanjutnya muncul tokoh lain yang mengganggu Jepaplok agar pergi dari desa tersebut, selain itu dua pemain juga menunjukan unjuk kebolehannya melakukan antraksi-atraksi yang yang sifatnya membuat penoton tertawa ketika menyaksikannya, seperti adegan salto, dan bergaya seperti badut. 


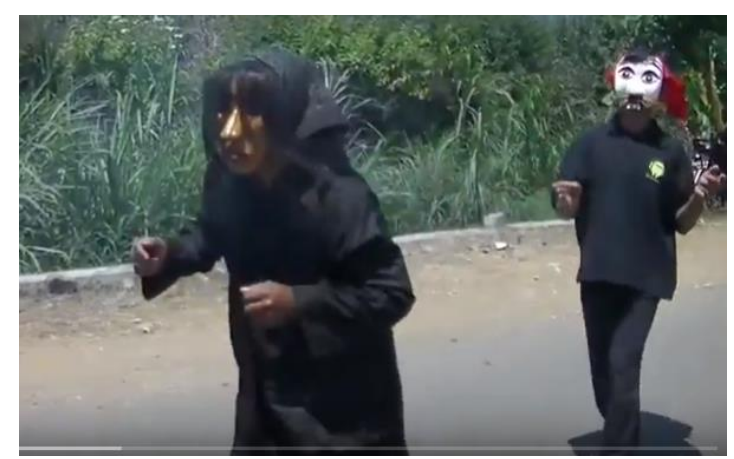

Gambar 2

Dua karakter juga menunjukan unjuk kebolehannya melakukan adegan lucu (Dokumentasi Penulis 2017)

Struktur penari pentul dan tembem sengaja keluar secara bersamaan dengan maksud mengusir jepaplok, sebab jepaplok disini merupakan penggambaran dari seekor ular yang suka memakan ternak milik masyarakat desa Slaharwotan. Sehingga penari pentul dan tembem bisa di artikan sebagai penasehat bagi para petani.

d) Adegan genderuwonan ini merupakan babak terakhir dalam pertunjukan Gemblak Dor. Tokoh genderuwo ini juga melakukan adegan trance atau kesurupan sama halnya dengan Jaranan dan Jepaplokan. Karakter tokoh genderuwo ini, terkadang gejul dan menakut-nakuti penonton seperti menggoda penonton dengan menggerakkan topengnya yang berwajah seram. Pada klimaks babak terakhir tokoh genderuwo juga disadarkan oleh seorang pawang

\section{Penutupan}

Penutupan seni pertunjukan Gemblak Dor ini diakhiri dengan keluarnya semua tokoh-tokoh yang ikut serta dalam pertunjukan tersebut, berbaris berjajar kemudian pemimpin pertunjukan mengucapkan salam penutup, dan penonton bubar dari area pertunjukan. Setelah melakukan penghormatan para pemain melakukan do'a bersama sebagai ungkapan terimakasih kepada Tuhan Yang Maha Esa karena telah diberi kelancaran dalam pementasan tersebut. 


\section{Elemen-elemen Pendukung}

\section{Tata Pentas}

Seni pertunjukan Gemblak Dor yang berau magis ini, dipentaskan dengan bersetting alam terbuka (tanah lapang). Disamping itu, tempat pertunjukan Gemblak Dor juga disesuaikan dengan formasi pemain, tata letak pemukul instrumen, dan penari.

\section{Tata Rias}

\section{a) Penari Ayon-ayon}

Seni pertunjukan Gemblak Dor yang berau magis ini, dipentaskan dengan bersetting alam terbuka (tanah lapang). Disamping itu, tempat pertunjukan Gemblak Dor juga disesuaikan dengan formasi pemain, tata letak pemukul instrumen, dan penari

\section{b) Tata Rias Jaranan}

penari jaranan memakai rias gagah alus, dengan alis dipertebal dan dipertegas, menggunakan godek, memakai kumis dan sedikit janggut tipit dengan menngunakan pensil alis berwarna hitam, ditambah eye shadow warna hitam.

\section{Tata Busana}

\section{a) Penari Ayon-ayon}

Busana yang digunakan penari ayon-ayon yaitu:

Baju lengan pendek, Celana Panjang, kain wiru, stagen, sabuk, kalung kace, pos deker, gelang kaki, udeng.

\section{b) Penari jaranan}

Busana yang digunakan penari jaranan, yaitu udeng, celana pendek, lengan panjang, rapek, dan jarik

\section{c) Jepaplok, pentul, dan tembem}

Untuk penari jepaplok, pentul, dan tembem, karane meraka menggunakan topeng sehingga memakai sragam yang sama yaitu : baju larik dan celana panjen.

\section{4) Genderuwo}

Busana yang dikenakan genderuwo terbuat dari karung yang disuir-suir sebagai penegas bahwa tokoh genderuwo sangat menyeramkan.

\section{5) Pawang}

Celana yang digunakan seperti celana yang digunakan oleh warok, berwarna hitam polos (komprang). 


\section{6) Pengarwit}

Busana pengrawit menggunakan atasan seragam dan bawahnya memakai celana panjang berwarna hitam dan memakai udeng batik

\section{Tokoh}

\section{a) Ayon-ayon}

. Ayon-ayon berarti "Аyu-ayu" atau penggambaran keindahan dewa padi atau bisa disebut dengan Dewi Sri. Dahulu penari Ayon-ayon ini ditarikan oleh seorang lakilaki, namun karena sekarang sudah ada penari perempuan sehingga diganti dengan penari perempuan.

\section{b) Jaranan}

Tari jaranan merupakan tarian yang menggambarkan seorang prajurit. Penari jaranan diperankan oleh seorang laki-laki, pola geraknya bersumber dari gerak seharihari yang biasa dilakukan oleh masyarakat yang bekerja sebagai petani. Gerakan yang dominan ada pada bagian gerakan kaki hal ini bisa di lihat dari seorang petani yang pulang dan pergi ke sawah. Selain gerakan kaki tarian jaranan ini juga ditekankan pada gerakan kepala, sehingga ketika kaki bergerak maka kepala juga digerakkan secara bergantian.

\section{c) Jepaplok}

Tokoh Jepaplokan ini merupakan penggambaran dari Ular binatang buas yang suka memakan tanaman petani juga hewan ternak yang dipelihara oleh seorang petani. Tokoh jepaplokan ini dibawakan oleh satu orang penari dengan membawa topeng sebagai properti kepala ular.

\section{d) Pentul dan Tembem}

Tokoh topeng Pentul dan Thembem ini merupakan penggambaran dari anak salah satu Selir raja Kediri, nama aslinya yaitu Bancak dan Doyok karena wajahnya yang tidak tampam, sehingga Pentul dan tembem ini memutuskan untuk menjadi prajurit.

\section{e) Genderuwo}

Genderuwo merupakan gambaran makhluk halus yang menakutkan bagi manusia yang harus disingkirkan. Tokoh genderuwo ini menggunakan topeng raksasa, gerakannya pun hanya sekedar berjalan menggelilingi area pertunjukan, 
meakukan atraksi-atraksi seperti salto, menakut-nakuti penonton, dan mengalami trance.

\section{Pola Lantai}

\section{a) Ayon-ayon}

Pola lantai yang digunakan penari ayon-ayon, yaitu berderet memutari area lapangan dengan jalan ngincik seperti orang yang mengendarai kuda, kemudian berhenti ditempat dengan posisi berjajar dengan gerakan mengukel tangan kanan kiri, diikuti dengan kepala serta kaki yang berjalan ditempat dengan mapak.

\section{b) Jaranan}

Pola lantai pada penari jaranan ada tiga macam, yaitu berjajar dengan gerakan memantulkan kaki kanan kiri secara bergantian dengan menunggang kuda, kemudian pada pola lantai kedua yaitu berhadapan seperti gerakan gelutan, kemudian mengalami trance, dan yang terakhir yaitu berderet dengan gerakan ngincik.

\section{c) Jepaplok}

Penari jepaplok menggunakan topeng yang menggambarkan ular naga, gerakannya bebas di area pentas, seperti meliuk-liukan topeng yang dibawanya mengitari area lapang dan mengalami trance dipinggir kiri area pementasan.

\section{d) Pentul dan Tembem}

Tokoh pentul dan tembem ini, keluar bersamaan dengan jepaplok mengikuti dibelakangnya namun, kedua tokoh ini juga bergerak bebas di area pementasan, terkadang juga mendekati dan menggoda penonton.

\section{e) Genderuwo}

Pola lantai untuk genderuwo, bergerak bebas di area pementasan terkadang berjalan mengeliling area tempat pementasan, kemudian berhenti ditengah-tengah area melakukan trance.

\section{Gerak}

\section{a) Ayon-ayon}

Gerak yang dilakukan oleh penari ayon-ayon dalam pertunjukan Gemblak Dor yaitu menari dengan membawa kuda sebagai properti. Gerakannya sangat sederhana 
yaitu mengukel tangan kanan dan kiri secara bergantian, kepala juga ikut beriringan dengan gerakan tangan, dan kaki berjalan mapak .

\section{b) Jaranan}

Gerakan penari jaranan bersumber dari gerakan sehari-hari yang biasa dilakukan oleh masyarakat yang bekerja sebagai petani seperti pada gerakan kaki, berjalan ngincik. Hal ini bisa dilihat dari seorang petani yang pulang dan pergi ke sawah. Selain itu gerakannya lebih ditekankan pada gerakan kepala yang sering digerakan ke depan belakang beriringan dengan gerakan kaki, sehingga ketika kaki bergerak maka kepala juga ikut begerak. Ciri khas dari gerakan jaranan ini, meletakkan kuda sebagai propertinya di pinggang dengan bentuk kaki tanjak, selanjutnya selain dengan tanjak juga dengan jengkeng.

Ketika irama kendang rangkep gerakan penari jaranan yaitu dengan trecet ditempat, posisi kuda masih diletakkan dipinggang. Sesekali dua penari jaranan juga bersingkuran menyatukan kepala kuda layaknya kuda yang ingin bertarung.

\section{c) Jepaplok}

Gerak penari jepaplok menyesuaikan dengan karakter topengnya. Struktur gerakan Jepaplok digerakkan meliuk-liuk dengan kepalanya serta gerakan mulut dari topeng tersebut yang terkadang menutup dan membuka (nyatek). Hal ini sesuai dengan karakter dari penggambaran seekor ular yang senang memangsa hewan peliharaan seorang petani.

Gerakan jepaplok disini tidak menggunakan kiprahan seperti jepaplok yang ada dalam pertunjukan jaranan pada umumnya. Ketika memasuki area pementasan penari jepaplok langsung menggerakkan topengnya seperti penari barongsai.

\section{d) Pentul dan Tembem}

Penari pentul dan tembem ini gerakannya sangat gejul dengan melakukan atraksi seperti salto, menggoda penonton seperti badut dengan maksud mengajaknya ikut menari bersama. Gerakan yang dimunculkan oleh penari pentul dan tembem juga mengikuti gending yang dimainkan, menggerakkan tangannya dengan mengukel secara bergantian, terkadang juga menirukan iringan kendang yang dimainkan, misalkan bunyi jidor dengan suara "Dor" maka gerakan pentul dan tembem menggoyangkan pinggulnya ke kanan dan ke kiri, sehingga membuat penonton merasa terhibur dan ikut berinteraksi. 


\section{e) Genderuwo}

Gerakan yang dimainkan oleh genderuwo, dia hanya sekedar berjalan dan menakut-nakuti para penonton, namun terkadang juga bergerak sangat lucu sehingga membuat penonton tertawa karena terhibur.

\section{Properti}

Properti yang digunakan dalam seni pertunjukan Gemblak Dor adalah: kuda kepang, pecut, topeng jepaplok, pentul, dan tembem, Genderuwo.

\section{Sesaji}

Sesaji yang digunakan dalam pertunjukan Gemblak Dor adalah:

a) Beras Kuning

Beras kuning sebagai pelambang penyucian, menyingkirkan segala hal negatif yang ada di lingkungan sekitar.Beras kuning dalam pertunjukan Gemblak Dor ini digunakan diawal pertunjukan ketika pawang membakar dupa atau menyan, sebelum memutar-mutarkan pecut diatas kuda yang diparkir di tengah area pementasan.

b) Minyak wangi

Minyak wangi sebagai gambaran menyebarluaskan yang baik dan menghilangkan hal-hal yang tidak baik. Minyak wangi dalam pertunjukan Gemblak Dor ini merupakan bau yang mengundang roh halus (bau mistik). Minyak wangi juga juga ditaburkan pada properti pecut guna menyetir pemain Gemblak Dor yang sedang trance.Selain untuk mengundang roh halus, minyak wangi juga digunakan pawang sebagai sarana menyadarkan para pemain Gemblak Dor yang sedang kesurupan, dengan menciumkan minyak wangi ke hidung pemain yang mengalami trance.

\section{Musik Pengiring}

Alat musik yang digunakan dalam seni pertunjukan Gemblak Dor adalah: kendang, jidor, cimplung, slumpret, dan saron.

\section{Fungsi Seni Pertunjukan Gemblak Dor}

1. Fungsi Primer (ritual, hiburan, dan sarana presentasi estetis)

2. Fungsi Sekunder ( pengikat solidaritas kelompok masyarakat dan sarana komunikasi)

Peneliti juga menemukan fungsi baru yaitu, sebagai respon fisik. 


\section{PENUTUP}

\section{Simpulan}

1. Seni pertunjukan Gemblak Dor ini merupakan akulturasi budaya yang dibawa masuk ke Lamongan oleh sekelompok pengamen dari Jombang dan Nganjuk, kemudian berkembang di kecamatan Modo, Bluluk, Sukorame, dan Ngimbang.

2. Bentuk Pertunjukan Gemblak Dor terdiri dari : Struktur Pertunjukan yang berisi (Pembukaan, Pertunjukan, dan Penutupan) dan elemen-elemen pendukung pertunjukan (tat pentas, tat rias, tata busana, gerak, pola lantai, penokohan, sesaji, properti, musik pengiring, alat musik, dan penonton)

3. Berkaitan dengan fungsi seni pertunjukan Gemblak Dor di desa Slaharwotan terdapat beberapa fungsi yang terdiri dari : (1) Fungsi Primer meliputi (fungsi ritual, fungsi hiburan, dan Pressentasi Estetis) (2) Fungsi Sekunder yang meliputi (fungsi pengikat solidaritas masyarakat, dan komunikasi), Selain fungsi primer dan sekunder peneliti juga menemukan fungsi baru, yaitu berfungsi respon fisik.

Seni Pertunjukan Gemblak Dor di Desa Slaharwotan Kecamatan Ngimbang Kabupaen Lamongan, saat ini mengalami perkembangan yang baik sekali, minat masyarakat untuk menanggap seni pertunjukan ini sangat baik lagi, yang biasanya hanya pentas di desa-desa sekitar sekarang sudah mulai mengisi acara minggu ceria yang biasanya diadakan di alun-alun Lamongan.

\section{Saran}

Berdasarkan pengalaman peneliti selama melakukan penelitian hingga menganalisis seni tradisional kerakyatan yang berupa seni pertunjukan Gemblak Dor, khususnya pemerintah daerah kabupaten Lamongan melalui Dewan Kesenian Lamongan, dalam menggali dan mereilitasi seni pertunjukan akan terwujud bila masing-masing daerah masih bersedia menerima bentuk dan keberadaan seni perunjukan tersebut, serta melestarikan, mengembangkan dan mewariskan kepada generasi berikutnya. Dan sudah selayaknya pihak-pihak yang terkait memperhatikan dan mengulurkan tangan, serta secara intensif pendokumentasian aset-aset kebudayaan, kesenian maupun seni tradisi yang dimilikinya, baik berupa situs-situs budaya, kesenian khas daerah maupun pengkajian secara ilmiah. Demikian masyarakat khususnya Lamongan, agar senantiasa menjaga, melestarikan dan 
mengembangkan aset-aset kebudayaan, kesenian daerah secara intensif harus dilakukan, apapun bentuk dan keberadaannya serta eksistensinya.

\section{DAFTAR RUJUKAN}

Bungin, Burhan. 2012. Analisis Data Penelitian Kualitatif.Jakarta : PT RAJAGRAFINDO PERSADA.

Brandon, James R.2003. Jejak-jejak Seni Pertunjukan di Asia Tenggara. Bandung : P4ST UPI

Djelantik, A.A.M. 1999. Estetika Sebuah Pengantar. Bandung : Masyarakat seni pertunjukan Indonesia dan Arti.

Geertz Cliford. 1898. Abangan, Santri, Priyayi Dalam Masyarakat Jawa.Jakarta: PT Midas Surya Grafindo.

Hidayat, Robby. 2005. Wawasan Seni Tari. Malang : Jurusan Seni dan Desain Fakultas Sastra Universitas Malang.

Jazuli, M. 1994. Telaah Teoritis Seni Tari. Semarang : IKIP Semarang Press.

Kardiyanti, Oktaviana. 2006 “Revitalisasi Jaranan Dalam Kepang Dor oleh Dinas Pendidikan dan Kebudayaan Kabupaten Lamongan".Skripsi : Tidak diterbitkan.

Moleong, Lexy J. 2014. Metodologi Penelitian Kualitatif edisi Revisi. Bandung: Remaja Rosdakarya.

Ningtyas, Ayu. 2005. "Seni Pertunjukan Barongan Di Desa Jombok Kecamatan Jatirogo Kabupaten Tuban”. Skripsi : Tidak diterbitkan.

Padmodarmaya, Pramana. 1998. "Tata dan Teknik Pentas”. Jakarta: Balai Pustaka.

Poerwadarminta, W. J.S. 1984. Kamus Umum Bahasa Indonesia. Jakarta: PN Balai Pustaka.

Riduwan.2004. Metodologi dan Riset Data. Alumni: Bandung.

Rusmaningrum, Riska Novia. 2013. "Bentuk Penyajian Kesenian Jaranan Jawa Di Desa Pakunden Kecamatan Pesantren Kota Kediri”. Skripsi : Tidak diterbitkan.

Sedyawati, Edi. 1981. Pertumbuhan Seni Pertunjukan. Jakarta: Sinar Harapan.

Soedarsono, R.M. 2001. Seni Pertunjukan Indonesia di Era Globalisasi. Jakarta: Ditjen Dikti Depdikbud.

Sugiyono. 2014. Memahami Penelitian Kualitatif Bandung: Alfabeta. 
Sugiyono, 2006. Metode Penelitian Kuantitatif Kualitatif Dan $R$ \& D. Bandung: Alfabeta.

Tim Redaksi Majalah Dinamika Guru. 2014. Pemikiran Guru Ponorogo Untuk Indonesia. Yogyakarta: Araska.

Wahyudiyanto. 2008. Pengetahuan Tari. Surakarta: ISI Press Solo dan CV Cendrawasih. 